\title{
Advanced Healthcare Materials
}

\section{Liquefied microcapsules as dual-microcarriers for 3D+3D bottom-up tissue engineering --Manuscript Draft--}

Manuscript Number:

Full Title:

Article Type:

\section{Section/Category:}

Corresponding Author:

Additional Information:

Question

Please submit a plain text version of your cover letter here.
Keywords:

adhm.201901221R1

Liquefied microcapsules as dual-microcarriers for 3D+3D bottom-up tissue engineering

Full Paper

Cell encapsulation, bottom-up tissue engineering, microparticles, osteogenic differentiation, co-culture

Clara R Correia, MSc, PhD

Universidade de Aveiro CICECO

Aveiro, Aveiro PORTUGAL

\section{Response}

Dear editor,

We present the manuscript entitled "Liquefied microcapsules as dual-microcarriers for 3D+3D bottom-up tissue engineering" that we would like you to consider for resubmission in Advanced Healthcare Materials (adhm.201900795, editor: Dr. Uta Goebel). We performed all the minor corrections detected by the reviewer, as specified in the "point-by-point response" document. Additionally, we performed two minor corrections in the figures:

- Figure 3E: the weight of the arrow was increased for enhance the visualization of the object;

- Figure S1: a new block showing the top-view visualization of the capsules was added to clarify design of the experiment.

We are fully available to provide any further information you may need.

Sincerely,

Clara R. Correia (Junior Researcher) and João F. Mano (Full Professor)

CICECO-Aveiro Institute of Materials, Dept. Chemistry, University of Aveiro, Aveiro, Portugal

No. The authors declare no conflict of interest.

Do you or any of your co-authors have a conflict of interest to declare?

Corresponding Author Secondary Information:

Corresponding Author's Institution:

Universidade de Aveiro CICECO

Corresponding Author's Secondary Institution:

First Author:

Clara R Correia, MSc, PhD

First Author Secondary Information:

Order of Authors:

Clara R Correia, MSc, PhD

Isabel M. Bjørge, MSc

Jinfeng Zeng 
Michiya Matsusaki

João F. Mano, BSc, MSc, PhD, Full Professor

Order of Authors Secondary Information:

\begin{tabular}{|c|c|}
\hline Abstract: & $\begin{array}{l}\text { Cell encapsulation systems must ensure the diffusion of molecules to avoid the } \\
\text { formation of necrotic cores. The architectural design of hydrogels, the gold standard } \\
\text { tissue engineering strategy, is thus limited to a microsize range. To overcome such } \\
\text { limitation, liquefied microcapsules encapsulating cells and microparticles are proposed. } \\
\text { Microcapsules with controlled average diameters of } 608.5 \pm 122.3 \mu \text { m are produced at } \\
\text { high rates by electrohydrodynamic atomization, and RGD domains are introduced in } \\
\text { the multilayered membrane. While cells and microparticles interact towards the } \\
\text { production of confined microaggregates, on the outside cell-mediated } \\
\text { macroaggregates are formed due to the aggregation of microcapsules. The concept of } \\
\text { simultaneous aggregation is herein termed as } 3 D+3 D \text { bottom-up tissue engineering. } \\
\text { Microcapsules are cultured alone (microcapsule1) or on top of } 2 D \text { cell beds composed } \\
\text { of HUVECs alone (microcapsule2) or co-cultured with fibroblasts (microcapsule3). } \\
\text { Microcapsules are able to support cell encapsulation shown by LiveDead, MTS and } \\
\text { dsDNA assays. Only microcapsule } 3 \text { are able to form macroaggregates, as shown by } \\
\text { F-actin immunofluorescence. The bioactive } 3 D \text { system also presented alkaline } \\
\text { phosphatase activity, thus allowing osteogenic differentiation. Upon implantation using } \\
\text { the chick chorioallontoic membrane (CAM) model, microcapsules recruit a similar } \\
\text { number of vessels with alike geometric parameters in comparison with CAMs } \\
\text { supplemented with bFGF. }\end{array}$ \\
\hline
\end{tabular}


Dear editor,

We present the manuscript entitled "Liquefied microcapsules as dual-microcarriers for $3 D+3 D$ bottom-up tissue engineering" that we would like you to consider for resubmission in Advanced Healthcare Materials (adhm.201900795, editor: Dr. Uta Goebel). We performed all the minor corrections detected by the reviewer, as specified in the "point-by-point response" document. Additionally, we performed two minor corrections in the figures:

- Figure 3E: the weight of the arrow was increased for enhance the visualization of the object;

- Figure S1: a new block showing the top-view visualization of the capsules was added to clarify design of the experiment.

We are fully available to provide any further information you may need.

Sincerely,

Clara R. Correia (Junior Researcher) and João F. Mano (Full Professor)

CICECO-Aveiro Institute of Materials, Dept. Chemistry, University of Aveiro, Aveiro, Portugal 


\title{
WILEY-VCH
}

Liquefied microcapsules as dual-microcarriers for 3D+3D bottom-up tissue engineering

Clara R. Correia ${ }^{a^{*}}$, Isabel M. Bjørge ${ }^{a}$, Jinfeng Zeng ${ }^{b}$, Michiya Matsusaki ${ }^{b, c, d}$, João F. Mano ${ }^{a^{*}}$

Dr. C.R. Correia*, I.M. Bjørge, and Professor J.F. Mano*

CICECO-Aveiro Institute of Materials, Department of Chemistry, Campus Universitário de Santiago, 3018-193 Aveiro, Portugal

E-mails: claracorreia@ua.pt and jmano@ua.pt

Dr. J. Zeng

Osaka University, Joint Research Laboratory (TOPPAN) for Advanced Cell Regulatory Chemistry, Graduate School of Engineering, Japan

Professor M. Matsusaki

Osaka University, Joint Research Laboratory (TOPPAN) for Advanced Cell Regulatory Chemistry, Graduate School of Engineering, Japan

Division of Applied Chemistry, Graduate School of Engineering, Osaka University, Japan JST, PRESTO, Japan

Keywords: microcapsules, cell encapsulation, layer-by-layer, bottom-up tissue engineering, 3D systems

\begin{abstract}
Cell encapsulation systems must ensure the diffusion of molecules to avoid the formation of necrotic cores. The architectural design of hydrogels, the gold standard tissue engineering strategy, is thus limited to a microsize range. To overcome such limitation, liquefied microcapsules encapsulating cells and microparticles are proposed. Microcapsules with
\end{abstract}




\section{WILEY-VCH}

controlled sizes with average diameter of $608.5 \pm 122.3 \mu \mathrm{m}$ are produced at high rates by electrohydrodynamic atomization, and RGD domains are introduced in the multilayered membrane. While cells and microparticles interact towards the production of confined microaggregates, on the outside cell-mediated macroaggregates are formed due to the aggregation of microcapsules. The concept of simultaneous aggregation is herein termed as 3D+3D bottom-up tissue engineering. Microcapsules are cultured alone (microcapsule ${ }^{1}$ ) or on top of 2D cell beds composed of HUVECs alone (microcapsule ${ }^{2}$ ) or co-cultured with fibroblasts $\left(\right.$ microcapsule ${ }^{3}$ ). Microcapsules are able to support cell encapsulation shown by LiveDead, MTS and dsDNA assays. Only microcapsule ${ }^{3}$ are able to form macroaggregates, as shown by F-actin immunofluorescence. The bioactive 3D system also presented alkaline phosphatase activity, thus allowing osteogenic differentiation. Upon implantation using the chick chorioallontoic membrane (CAM) model, microcapsules recruit a similar number of vessels with alike geometric parameters in comparison with CAMs supplemented with bFGF.

\section{Introduction}

Liquefied cell culture systems have emerged as an alternative to solve some specific drawbacks presented by the classical 3D tissue engineering strategies, namely the encapsulation of cells within hydrogels. ${ }^{[1]}$ The main advantages of hydrogels as cell encapsulation matrixes are their hydrophilic nature, and their ability to provide a three-dimensional (3D) environment. However, key parameters when designing hydrogels include architectural factors, such as size and porous structure, which are limited to a specific range due to mass transportation concerns. ${ }^{[2]}$ If cells encapsulated at the core are deprived from a proper diffusion of essential molecules, they will inevitably undergo apoptosis. Liquefying the core of hydrogels seemed a logical and simple approach, however, long-term application of such systems failed because all normal tissuederived cells, excepting hematopoietic progenitor cells, are anchorage-dependent. When deprived from a physical support, these cells are not able to proliferate, and consequently 


\section{WILEY-VCH}

undergo anoikis. ${ }^{[3]}$ In the last years, we have been successfully exploring an alternative approach that combines the advantages of hydrogels, liquefied systems, and microcarriers. Besides solving the limited diffusion of hydrogels, liquefied capsules also allow the encapsulated cells to self-organize within the liquefied core, rather than pre-establishing their 3D organization. Additionally, liquefied capsules can be implanted by injection, thus allowing minimal invasive procedures, even when presenting macrosize diameters ${ }^{[4]}$. We established the concept of liquefied and multilayered capsules, with promising results in vitro and in vivo for general or more applied tissue engineering strategies for cartilage and bone regeneration. ${ }^{[4-8]}$ The concept relies on the use of alginate hydrogels as temporary hydrophilic 3D structure to encapsulate cells and microparticles. After the build-up of a multilayered membrane, the core can be subsequently liquefied by a simple mild process. The nanostructure of this membrane assures the rapid exchange of biomolecules essential for long-term cell survival and signaling. The encapsulated microparticles act as cell microcarriers by providing the physical support required for cells to survive. Within the liquefied core, cells can move freely, interact directly with other co-encapsulated cells, and, most importantly, create cell-mediated aggregates by recruiting the encapsulated microparticles. Of note, cells encapsulated in such bioencapsulation system showed enhanced metabolic activity, and proliferation compared to cells encapsulated in non-liquefied alginate hydrogels or in liquefied capsules without microparticles ${ }^{[4]}$.

Here, we intend to boost the liquefied and multilayered capsules concept towards their clinical application by proposing a high rate production method. Additionally, we aim to design capsules with a bioactive outer membrane, which would present cell adhesive properties and allow to improve the agglomeration and integration of microcapsules within the surrounding tissue. Figure S1 shows a schematic representation of the production of the multilayered and liquefied microcapsules, and the experimental design of the present study. Electrohydrodynamic atomization (EHDA) principles were applied to produce microcapsules. Then, a multilayered membrane was produced by the assembly of three polyelectrolytes, 


\section{WILEY-VCH}

namely poly(L-lysine), alginate, and chitosan, by the layer-by-layer (LbL) technique. The last alginate layer was then functionalized with the arginyl-glycyl-aspartic acid (RGD) domain, the most common peptide motif responsible for cell adhesion to the extracellular matrix (ECM). Then, microcapsules were placed on the top of previously formed 2D cell beds composed by HUVECs alone or co-cultured with fibroblasts. Inspired in a concept here termed as 3D+3D, we hypothesized that while within the inside of the liquefied core cells and microparticles would interact and create 3D microstructures, at the same time, microcapsules could interact to create macro 3D structures from the outside. Additionally, upon implantation, the bioactive outer membrane could also improve the microcapsules interaction with the surrounding tissue, contributing to a proper integration and regeneration. This hierarchical 3D macro-and-micro organization should be exclusively cell-mediated. Upon implantation, we envisage that the bioinspired vascularization substrate provided by the RGD-LbL of microcapsules would promote the recruitment of vessels and other cells involved in the cascade of the regenerative process, promoting tissue healing and integration. Simultaneously, new microaggregates of cells and microparticles could be form inside the microcapsules, which would also contribute to boost the healing process. Figure 1 summarizes the proposed 3D+3D concept allowing macro-andmicro simultaneous regeneration. The ability of microcapsules to allow cell adhesion on the outer LbL membrane was tested in vitro. For that, a cell bed composed by the sequential seeding of human fibroblasts and human umbilical vein endothelial cells (HUVECs) was developed. The combination of the cell bed and the microcapsules system is here termed as microcapsule ${ }^{3}$. Microcapsules cultured only with HUVECs (microcapsule ${ }^{2}$ ) or alone (microcapsule ${ }^{1}$ ) were used as controls. As a proof-of-principle, MC3T3-E1 cells were encapsulated with surface

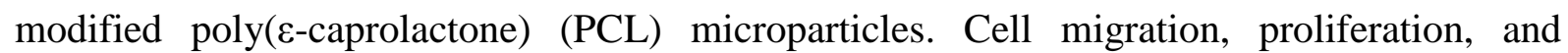
differentiation were evaluated in vitro up to 21 days post-encapsulation. The pro-angiogenic ability of the system was also tested in ovo using the chick chorioallantoic membrane (CAM) assay. 


\section{WILEY-VCH}

\section{Results}

\subsection{Optimum conditions for the production of spherical microgels}

To assess the optimum conditions for the production of microgels with the desired morphology and size, an alginate solution was electrosprayed under different flow rates $(30,40,50$, and 60 $\left.\mathrm{mL} \cdot \mathrm{h}^{-1}\right)$, polymer concentrations $(1.5$ and $2 \% \mathrm{w} / \mathrm{v})$, distances between the tip to the collector (TTC 6, 7, and $8 \mathrm{~cm}$ ), and applied voltages $(10,15$, and $20 \mathrm{kV})$. A library of microgels with varying morphologies and sizes was obtained. Figure 2A shows representative images of the optimization process (constant parameters: $50 \mathrm{~mL} \cdot \mathrm{h}^{-1}, 2 \% \mathrm{w} / \mathrm{v}, 6 \mathrm{~cm}$, and $10 \mathrm{kV}$ ) and a schematic representation of the EHDA set-up. The comprehensive understanding of the fundamentals of the EHDA process is well-described elsewhere. ${ }^{[9,10]}$ Our findings showed that the size of the microgels decreased as the polymer concentration increased. Additionally, below $2 \% \mathrm{w} / \mathrm{v}$ the microgels shifted from a circular morphology to a tear-like one. The stability of the jetting mode is highly affected by the voltage and the flow rate. Therefore, by controlling these two parameters monodisperse microgels can be obtained. For flow rates below $30 \mathrm{~mL} . \mathrm{h}^{-1}$ and applied voltages above $10 \mathrm{kV}$, polydisperse microgels were obtained (Figure 2A arrows). Higher flow rates also allowed to obtain microgels in a high-throughput fashion, which was a key factor in the optimization strategy implemented, since the obtained microgels were templates for the production of a cell encapsulation system composed by liquefied microcapsules. At a stable jetting mode, higher flow rates led to the formation of microgels with increased diameters. On the other hand, increasing the TTC distance decreased the strength of the electrical field, and thus higher and/or polydisperse microgels were obtained (Figure 2A arrows). Another key parameter influencing the EHDA process is the solution conductivity. Therefore, when microparticles were loaded into the alginate solution, the EHDA was affected, as shown in Figure 2B2. Therefore, in order to obtain spherical microgels the concentration of alginate was increased to $2.25 \% \mathrm{w} / \mathrm{v}$. Then, by varying the TTC, microgels encapsulating 


\section{WILEY-VCH}

spherical microparticles (Figure 2B3) with an average diameter of $50 \pm 9 \mu \mathrm{m}$ (Figure 2B4) were obtained. As evidenced in Figure 2B5, monodisperse and circular microgels encapsulating microparticles could be obtained after increasing the TTC distance from $6 \mathrm{~cm}$, optimized for empty microgels, to $8 \mathrm{~cm}$. At $7 \mathrm{~cm}$, although spherical microgels could be obtained, the sample was heterogeneous (Figure 2B5 arrow). Below $7 \mathrm{~cm}$ and above $8 \mathrm{~cm}$, microgels presented a tear-like morphology. After the production of the multilayered membrane, microcapsules were immersed in EDTA to liquefy the alginate core. Consequently, the microparticles dispersed in the crosslinked alginate matrix of the spherical microgels (Figure S2A), agglomerate at the bottom of the spherical microgels (Figure S2B).

\subsection{D cell bed and microcapsules set-up}

Microcapsules encapsulating surface modified microparticles and cells were successfully produced, and visualized by LSCM after overnight incubation at $37^{\circ} \mathrm{C}$ in a humidified air atmosphere of $5 \% \mathrm{CO}_{2}$. The distribution of the encapsulated cells within the liquefied core of microcapsules was tracked by DAPI nuclei staining (Figure 3A blue spots). Importantly, after the EHDA process, the encapsulated cells remained alive, and therefore the parameters of the process, did not jeopardize cell viability (Figure 3B). Prior to the transfer of microcapsules, the last step of the sequential seeding, the engineered cellular environment on the outside environment of microcapsules, termed as cell bed, was evaluated. For that, HUVECs were stained with DiL and their morphology and expression of CD31 was assessed when cultured alone or in a co-culture with fibroblasts (Figure 3C and 3D). As shown, HUVECs-DiL in the co-culture aligned within the extracellular matrix of fibroblasts and presented a more elongated morphology compared to the mono-culture. Additionally, a higher expression of CD31 could be found in the co-culture. To assess the co-localization of the different cells within the triple co-culture system, each cell phenotype was previously stained with a lipophilic dye, namely with DiO, DiL, and DiD for fibroblasts, HUVECs, and MC3T3-E1, respectively. As shown, 


\section{WILEY-VCH}

MC3T3-E1 encapsulated within the liquefied core of microcapsules are localized at the top of the cell bed composed by fibroblasts and HUVECs (Figure 3E). Interestingly, HUVECs and fibroblasts co-exist within the same plane, as shown in Figure 3E $\mathrm{zx}$ and $\mathrm{zy}$, showing that HUVECs occupied the space left by fibroblasts. Additionally, the alignment of HUVECs within the fibroblasts extracellular matrix is observed in Figure 3E xyz. Interestingly, in Figure 3E zx and zy fibroblasts and HUVECs could already be detected adhered to the microcapsules, although the majority still remained at the bottom of microcapsules, showing that cells migrated from the $2 \mathrm{D}$ environment towards the $3 \mathrm{D}$ structure of microcapsules.

Microcapsules with an alginate last layer lacking the RGD motif were also produced to assess if the previously formed 2D cell beds were able to adhere to the surface of such microcapsules. For that, microcapsules composed by a multilayered membrane ending in the poly(L-lysine) polyelectrolyte were produced. Poly(L-lysine) is widely used as a coating material known to favor cell adhesion. However, HUVECs alone or co-cultured with fibroblasts remained adhered to the 2D surface and thus did not migrated towards the multilayered membrane of microcapsules (Figure S3). Through the transparent core of the liquefied microcapsules, it is possible to observe that in the $2 \mathrm{D}$ cell bed composed by HUVECs alone, cells presented a rounded morphology (Figure S3A), contrary to the stretched morphology observed for the 2D cell bed composed by fibroblasts and HUVEC (Figure S3B).

\subsection{In vitro bioperformance}

The ability of microcapsules to perform as a dual micro-carrier system for tissue engineering was assessed. The ability of microcapsules to support living cell encapsulation was assessed up to 21 days post-encapsulation. Cell viability and proliferation were evaluated by MTS (Figure 4A) and DNA (Figure 4B) quantification assays, respectively. Different microcapsule 


\section{WILEY-VCH}

formulations cultured in basal (bas) or osteogenic differentiation (osteo) media were tested, namely $(i)$ microcapsule ${ }^{3}$ - microcapsules encapsulating MC3T3-E1 and containing a co-culture of fibroblasts and HUVECs adhered to the external membrane, (ii) microcapsule ${ }^{2}$ microcapsules encapsulating MC3T3-E1 and containing HUVECs adhered to the external membrane, and (iii) microcapsule ${ }^{1}$ - microcapsules encapsulating MC3T3-E1 without cells on the external environment. Of note, MTS and DNA assays were quantified after transferring the samples in order to exclude the contribution resultant from the activity of cells that did not adhere to the membrane of microcapsules. For all the timepoints tested, microcapsule ${ }^{3}$ presented the highest metabolic activity levels, and microcapsule ${ }^{1}$ the lowest. With time, MTS values increase evidencing the ability of microcapsules to support living cell encapsulation. Microcapsules cultured in bas or osteo media presented similar metabolic activity. Regarding the ability of cells to proliferate (Figure 4B), at day 1 no significative differences were found between all the formulations tested. At day 3, such differences began to appear, with microcapsules $^{3}$ and microcapsules ${ }^{2}$ presenting the highest values compared to microcapsule ${ }^{1}$. The higher DNA content of microcapsule ${ }^{3}$ at days 14 and 21 post-encapsulation, can be explained by the adhesion of fibroblasts and HUVECs to the membrane. Likewise, microcapsules $^{2}$ presented a higher DNA content compared to microcapsule ${ }^{1}$, which could also have occurred due to the adhesion of HUVECs. However only a slight increase could be detected. When cultured in the external environment of capsules alone, HUVECs presented a rounded morphology and a poor migrating ability compared to the co-culture with fibroblasts. In fact, the adhesion of HUVECs to the membrane could hardly be detected, presenting a high similarity to microcapsule ${ }^{1}$ (Figure S4). Contrarily, cells in the external co-culture environment were able to adhere to the membrane of microcapsules (Figure 4D), and after overnight incubation cell were able to migrate from the $2 \mathrm{D}$ cell bed to the $3 \mathrm{D}$ environment provided by microcapsules (Figure 4D squares). With time, macroaggregates composed by the assembling of microcapsules could be detected (Figure $4 \mathrm{E}$ and $4 \mathrm{H}$ ). These macroaggregates were cell- 


\section{WILEY-VCH}

mediated by the action of fibroblasts and HUVECs, which started to migrate from the cell network towards the membrane of the microcapsules that after $8 \mathrm{~h}$ of incubation (Figure 4F and 4I). This behavior occurred independently from the cell culture media used, whether bas or osteo media. While macroaggregates were formed due to the agglomeration of microcapsules, encapsulated cells simultaneously formed microaggregates by recruiting the co-encapsulated microparticles (Figure 4G and 4J, and Figure S4). Therefore, the proposed system allowed the simultaneous creation of cell-mediated macro (by agglomerating microcapsules) and micro (by agglomerating microparticles) aggregates. Additionally, the encapsulated cells were able to undergo cell differentiation towards the osteogenic lineage, as shown by the quantification of the activity of alkaline phosphatase (ALP) (Figure 4C). Of note, ALP activity peaks occurred at later timepoints, namely at days 14 and 21 post-encapsulation, but only when microcapsules were cultured in osteogenic differentiation medium.

\subsection{Angiogenic potential}

The angiogenic potential of microcapsules was assessed after in ovo implantation using the CAM assay (Figure 5). Remarkably, results show that microcapsules were able to recruit a similar number of new microvessels compared to CAMs without microcapsules and supplemented with basic fibroblast growth factor-2 (bFG-2, control +$)$. Since microcapsules were transferred to the CAM model in serum free $\alpha$-MEM, a negative control of CAMs supplemented with culture medium was also used (control -). The number of microvessels recruited by microcapsules was significantly higher compared to control -, evidencing that such differences were prompt by the microcapsule system itself, due to their functionalized RGD LbL membrane. Of note, only microvessels with a diameter below $20 \mu \mathrm{m}$ were considered for the quantification. Microvessels were quantified in a well-defined Region of Interest (ROI) for all conditions. The new vascular network formed within the ROI was similar to the vascular network formed by the control+ environment, in terms of the number of junctions (Figure 5D), 


\section{WILEY-VCH}

although no significative differences were found for both conditions compared to control-. Additionally, microcapsules prompted the formation of a vascular network composed by vessels with increased lengths compared to the control-.

\section{Discussion}

Liquefied and multilayered capsules have emerged as an alternative bioencapsulation system in which cells and microparticles are encapsulated in a liquefied environment. The system is composed by four main components, each one with specific functions, namely (i) a permselective multilayered membrane, (ii) microparticles, (iii) cells, and (iv) a liquefied core. The membrane is composed by chitosan, poly(L-lysine), and alginate electrostatically interacting by the LbL technique. It acts as a physical barrier that mediates the interaction between the inside and outside environment of capsules, thus avoiding the entrance of large molecules and other cells, while ensuring the permeability of essential molecules for long-term cell survival. Microparticles provide adhesion sites required for different biological processes of anchorage-dependent cells, both dispersed in the liquefied core. We already demonstrated the superior biological performance of liquefied and multilayered microcapsules coencapsulating cells and microparticles when compared to classical alginate hydrogels or with liquefied and multilayered microcapsules without microparticles ${ }^{[4]}$. Results showed that the system presented an enhanced metabolic activity, cell viability, and proliferation up to 28 days of in vitro culture. Cells and microparticles, encapsulated within the privilege liquefied environment of capsules can move freely, and macroaggregates containing cells and microparticles could be visualized by SEM or by fluorescence microscopy after F-actin staining. We believe that the established concept of liquefied and multilayered capsules as bioencapsulation system for regenerative medicine can find great applicability and value when used as building blocks to create complex 3D structures with clinical relevance. Therefore, we herein intend to take the concept of liquefied and multilayered capsules a step further by 


\section{WILEY-VCH}

proposing the combination of the high rate production of EHDA with the versatility and ease of the LbL technique to modify 3D structures. EHDA applied to produce cell encapsulation systems is often called bioelectrospraying (BES). Due to the low current of BES, the process enables to produce cell encapsulation systems with high cell viability. Xin et al. ${ }^{[11]}$ showed that up to $15 \mathrm{kV}$ and a TTC of $15 \mathrm{~cm}$, the viability and proliferation of six different cell types was not affected. Additionally, BES has also reported to do not affected the multilineage differentiation ability of mesenchymal stromal cells (MSCs). ${ }^{[12]}$ Herein, we used the BES technique to not only encapsulate cells but also microparticles. We optimized the parameters of the process to present the simplest set-up, rather than increasing its complexity by applying coaxial needles, high voltages or sheath gas. ${ }^{[13]}$ The proposed BES set up allowed to produce a library of spherical beads at high rates presenting different diameters (Figure 2). The rationale to select the optimized BES parameters to produce the hydrogel templates was a circularity close to 1 at the lowest voltage and highest flow rate, due to cell viability and scale-up concerns, respectively. Once the spherical hydrogels were obtained, a multilayered membrane was built by LbL technique. We have been employing this low cost and versatile technique to modify or construct 3D tissue engineering systems. ${ }^{[7,14-17]}$ Taking advantage of the versatility of the LbL technique, we conferred cell adhesion capability to the multilayered membrane simply by changing one of the polyelectrolyte solutions. Previously, we have reported the superior stability and an exponential regime growth of the multilayered membrane when combining three-polyelectrolytes, namely poly(L-lysine), chitosan, and alginate, compared to the classical two-system. ${ }^{[4]}$ Here, alginate combined with the well-known peptide sequence RGD was used to modify the last layer of the multilayered membrane of microcapsules. Our goal was to propose a dual-building block system by exploring the ability of microcapsules to produce microaggregates of cells and microparticles within the liquefied core, while at the same time, microcapsules could be assembled by cells and create macro and more complex 3D structures. Our in vitro results show the successful production and bioperformance of such system. The 


\section{WILEY-VCH}

superior organization of HUVECs when placed in a co-culture with fibroblasts (Figure 3D) was attributed to the ability of the later to provide important factors that modulate the growth and stability of capillary sprouts. ${ }^{[18]}$ Not limited to fibroblasts, other studies have also achieved tubular endothelial cell networks by co-culturing HUVECs with mesenchymal stromal cells. ${ }^{[19]}$ The production of microcapsules does not jeopardize cell viability, since cells remain metabolically active (Figure 4A) up to 21 days post-encapsulation. Additionally, cells are able to proliferate (Figure 4B). We also demonstrated that if desired, the encapsulated cells could undergo lineage differentiation (Figure 4C). However, peaks of ALP activity were only expressed when microcapsules were cultured in osteogenic differentiation medium. Previously, we reported that adipose-derived stromal cells encapsulated in liquefied and multilayered capsules could differentiate towards the osteogenic lineage in the absence of two major supplemental osteogenic differentiation factors, namely dexamethasone and ascorbic. ${ }^{[7,8]}$ Cell differentiation was prompted by the crosstalk of biomolecules, namely BMP-2 released by endothelial cells, when both cells were co-encapsulated within liquefied and multilayered capsules. Similarly, endothelial cells released VEGF, which could be detected on the outside environment of capsules, and thus the system was also validated to act as a release system of biomolecules. However, here such event did not occur since pre-osteoblastic cells and HUVECs were not co-encapsulated, and thus they were not in direct contact. The presence of the LbL membrane between these two cell phenotypes inhibited the formation of the gap junction connexin 43, a predominant gap junction protein in osteoblasts. Several studies demonstrate the ability of connexin 43 to form gap junctions between endothelial and osteogenic cells in direct co-culture. ${ }^{[20-25]}$ Of note, although the system has been validated for bone and cartilage regeneration, the modular ability of the liquefied microcapsules widely opens their applicability for different tissue engineering strategies. Either by changing the type of cells and microparticles encapsulated, or the type of functionalization employed to the multilayered membrane, a plethora of different cell encapsulation systems can be formulated. Besides 


\section{WILEY-VCH}

simultaneously conferring macro (Figure $4 \mathrm{E}$ and $4 \mathrm{H}$ ) and micro (Figure 4G, 4J and S4) cellmediated aggregation, liquefied and multilayered microcapsules also presented angiogenic ability, demonstrated in ovo using the CAM model (Figure 5). The pro-angiogenic ability of microcapsules conferred by the RGD-LbL membrane prompted an angiogenic response similar to that observed when CAMs where supplemented with bFG-2 (control+). This observation is supported by the similar number of microvessels that were recruited in microcapsules and control+ (Figure 5D). Additionally, geometrical parameters of the vasculature formed were also analyzed, namely the number of junctions and the branch length. The vasculature observed in microcapsules and control+ presented higher lengths compared to control -, which increases the possibility of branching to occur. We envisage that upon implantation in vivo, the proposed microcapsules would stimulate the recruitment of blood vessels. Angiogenic capacity of biomaterials is a key asset to attain full tissue functionality, not only due to the transport of essential molecules for cell survival but also to allow a proper tissue integration. ${ }^{[26]}$

The promising results obtained, makes us to believe that the proposed system once implanted would easily adapt to lesions with complex shapes, and recruit new vessels while also interacting with other cells involved in the cascade of the regenerative process. While aiding from the outside the healing of the tissue, on the inside, the new microaggregates of cells and microparticles formed would contribute to accelerate the process.

\section{Experimental Section}

Microparticles production and surface functionalization: Poly(e-caprolactone) (PCL) microparticles were produced by oil/water $(\mathrm{o} / \mathrm{w})$ emulsion technique, and surface modified by combining plasma treatment with collagen I as similarly described in our previous study. ${ }^{[4]} \mathrm{PCL}$ (5\% w/v, $\mathrm{M}_{\mathrm{n}} 80,000$, Merck) was dissolved in methylene chloride $\left(\mathrm{CH}_{2} \mathrm{Cl}_{2}\right.$, Honeywell Riedel- 


\section{WILEY-VCH}

de Haën $\left.{ }^{\mathrm{TM}}\right)$. Under agitation, this solution was added to polyvinyl alcohol (0.5\%, PVA, Merck).

After 2 days at RT, the produced microparticles were subsequently collected, washed with distilled water, and dried in ethanol. Microparticles were then placed in a plasma reactor chamber (ATTO, Diener Electronic) fitted with a radio frequency generator. Air was used as the working atmosphere. A glow discharge plasma (0.4 mbar, $30 \mathrm{~V})$ was created for 15 min. Subsequently, microparticles $(500 \mathrm{mg}$ ) were sterilized in $70 \% \mathrm{v} / \mathrm{v}$ ethanol, and immersed in collagen $\left(1200 \mu \mathrm{g}\right.$, type I solution from rat tail, Merck) diluted in acetic acid $(0.02 \mathrm{M})$ at $4^{\circ} \mathrm{C}$ overnight. The diameter of microparticles was measured by ImageJ software.

$2 D$ cell beds: Human fibroblasts (primary dermal fibroblasts, PCS-201-012, ATCC) were cultured in DMEM-high glucose (ThermoFisher Scientific) supplemented with FBS (10 \% v/v, ThermoFisher Scientific) and antibiotic-antimycotic (1\% v/v, ThermoFisher Scientific). At $\sim 80 \%$ confluency, cells were detached using trypsin-ethylenediaminetetraacetic acid (EDTA) (Merck) at $37^{\circ} \mathrm{C}$ for $5 \mathrm{~min}$. After $5 \mathrm{~min}$ of centrifugation at $300 \mathrm{~g}$, the supernatant was discarded. Cells (10,000 cells per well) were suspended in culture medium and seeded in $\mu$-slide 8 wells (ibidi). After $48 \mathrm{~h}$ of incubation $37^{\circ} \mathrm{C}$ in a humidified atmosphere composed of $5 \% \mathrm{CO}_{2}$, HUVECs (10,000 cells per well) were placed on top of fibroblasts. For that, HUVECs (PCS100-010, ATCC) cultured in M199 supplemented with FBS (20\% v/v), antibiotic-antimycotic (1\% v/v), GlutaMAX (1\% v/v, ThermoFisher Scientific), heparin sodium salt from porcine intestinal mucosa (180U, $10 \mathrm{mg} \cdot \mathrm{mL}^{-1}$, Merck), and endothelial cell growth supplement (Merck), were detached using trypsin-EDTA (Merck) at $37^{\circ} \mathrm{C}$ for $5 \mathrm{~min}$. After $5 \mathrm{~min}$ of centrifugation at $300 \mathrm{~g}$, the supernatant was discarded. Fibroblasts co-cultured with HUVECs were incubated in supplemented DMEM-high glucose and M199 (1:1). HUVECs were also cultured alone (10,000 cells per well) in supplemented M199 medium. After 48h of HUVECs seeding, liquefied and multilayered microcapsules were placed on top of $2 \mathrm{D}$ cell beds. 


\section{WILEY-VCH}

Liquefied and multilayered microcapsules: MC3T3-E1 cells (Subclone 4, ATCC CRL-2593) were cultured in Gibco® MEM $\alpha$ (ThermoFisher Scientific) supplemented with fetal bovine serum (FBS, $10 \% \mathrm{v} / \mathrm{v}$, ThermoFisher Scientific) and antibiotic-antimycotic (1\% v/v, ThermoFisher Scientific). At $\sim 80 \%$ cells were detached using trypsin-EDTA at $37^{\circ} \mathrm{C}$ for $5 \mathrm{~min}$. After 5 min of centrifugation at $300 \mathrm{~g}$, the supernatant was discarded. Cells were suspended in a solution containing sodium alginate $(2.5 \% \mathrm{w} / \mathrm{v}, \mathrm{W} 201502$, Merck $)$, sodium chloride $(0.15 \mathrm{M}$, $\mathrm{NaCl}$, LabChem), and MES hydrate (25 mM, Merck) at $\mathrm{pH}$ 6.7. Alginate microgels encapsulating cells $\left(1 \times 10^{6} \cdot \mathrm{mL}^{-1}\right)$ and microparticles $\left(30 \mathrm{mg} \cdot \mathrm{mL}^{-1}\right)$ were obtained by EHDA at $10 \mathrm{kV}, 8 \mathrm{~cm}$, and $50 \mathrm{~mL} \cdot \mathrm{h}^{-1}$ (total infused: $10 \mathrm{~mL}$ alginate). Prior to cell encapsulation, empty alginate microgels were also obtained for optimization procedures. For that, EHDA was tested using variable alginate concentrations (1.5 and $2 \% \mathrm{w} / \mathrm{v})$, voltage $(10,15$, and $20 \mathrm{kV})$, and distances between the tip to the collector (TTC, 6, 7, and $8 \mathrm{~cm}$ ). All microgels were collected in a stirring calcium chloride bath (0.1 M, Merck) buffered with MES hydrate (25 mM, Merck) at $\mathrm{pH}$ 7. After $15 \mathrm{~min}$ at RT, microgels were collected and rinsed in a washing solution of $\mathrm{NaCl}$ (0.15 M). The layer-by-layer membrane was obtained by subsequent adsorption of oppositely charged polyelectrolytes, namely first in poly(L-lysine) $\left(\mathrm{M}_{\mathrm{n}} 30,000-70,000, \mathrm{pH} 7\right.$, Merck), followed by peptide-coupled alginate (MVG GRGDSP, pH 7, Novatrix), water-soluble chitosan (pH 6, Protasan UP CL 213, NovaMatrix), and, ultimately, in peptide-coupled alginate again. The polyelectrolyte solutions $\left(0.3 \mathrm{mg} \cdot \mathrm{mL}^{-1}\right)$ were dissolved in $\mathrm{NaCl}(0.15 \mathrm{M})$ containing MES hydrate $(25 \mathrm{mM})$. Following $10 \mathrm{~min}$ of immersion for each polyelectrolyte, non-adsorbed macromolecules were removed by $\mathrm{NaCl}(0.15 \mathrm{M})$ rinsing. This process was repeated three times in order to obtain a 10-layered membrane. Microgels with a 9-layered membrane ending in the poly(L-lysine) polyelectrolyte were also produced (control). The coated microgels were immersed in EDTA (20 mM, Merck) at $\mathrm{pH} 7$ for 3 min to liquefy the alginate core. Ultimately, microcapsules were suspended in supplemented Gibco ${ }^{\circledR}$ MEM $\alpha(20 \mathrm{~mL})$ and transferred $(150$ $\mu \mathrm{L}$ per well) to the $\mu$-slide 8 wells containing the 2 cell beds with $(i)$ fibroblast co-cultured with 


\section{WILEY-VCH}

HUVECs (microcapsules ${ }^{3}$ ), or (ii) HUVECs (microcapsules ${ }^{2}$ ). Microcapsules were also transferred to wells without 2D cell beds (microcapsules ${ }^{1}$ ). All microcapsules were cultured in Gibco ${ }^{\circledR}$ MEM $\alpha$ supplemented with $10 \% \mathrm{v} / \mathrm{v}$ FBS and $1 \% \mathrm{v} / \mathrm{v}$ antibiotic-antimycotic, here termed as basal medium (bas), or in Gibco ${ }^{\circledR}$ MEM $\alpha$ supplemented with FBS $(10 \%$ v/v), antibiotic-antimycotic (1\% v/v), ascorbic acid $\left(50 \mu \mathrm{g} . \mathrm{mL}^{-1}\right.$, Merck), and $\beta$-glycerophosphate (10 mM, Merck), here termed as osteogenic differentiation medium (osteo).

Lipophilic dyes fluorescent labeling: Fibroblasts, HUVECs, and MC3T3-E1 were stained with lipophilic dyes 3,3'-dioctadecyloxacarbocyanine perchlorate (DiO, green), 1,1'-dioctadecyl3,3,3',3'-tetramethylindocarbocyanine perchlorate (DiL, red), and 1,1'-dioctadecyl3,3,3',3'-tetramethylindodicarbocyanine, 4-chlorobenzenesulfonate salt (DiD, blue), respectively. Cells were incubated with each dye $\left(1 \mathrm{~mL}\right.$ containing $2 \mu \mathrm{M}$ per $1 \times 10^{6}$ cells $)$ at $37^{\circ} \mathrm{C}$ for 15 min. Labeled cells were then used to construct the microcapsules ${ }^{3}$ system, and visualized by laser scanning confocal microscopy (LSCM, LSM 510 META, Zeiss).

Metabolic viability-based assay: the mitochondrial metabolic activity of the encapsulated cells was measured using the CellTiter $96 \AA$ AQueous One Solution Cell Proliferation Assay (Promega). At 1, 3, 7, 14, and 21 days post-encapsulation, microcapsules were aspirated and transferred to $1 \mathrm{~mL}$ centrifuge tubes. Following centrifugation at $300 \mathrm{~g}$ for $5 \mathrm{~min}$, the supernatant was discarded and samples were suspended in PBS containing 3-(4,5dimethylthiazol-2-yl)-5-(3-carboxymethoxyphenyl)-2-(4-sulphofenyl)-2H-tetrazolium (MTS, 1:6, $500 \mu \mathrm{L}$ ). After $4 \mathrm{~h}$ of incubation at $37^{\circ} \mathrm{C}, 100 \mu \mathrm{L}$ of each well (in quadruplicate) were transferred to a 96-well plate. The amount of formazan product was measured by absorbance at a wavelength of $490 \mathrm{~nm}$ using a multiwall spectrophotometer (Synergy HTX, Biotek). 


\section{WILEY-VCH}

Total dsDNA quantification and alkaline phosphatase activity (ALP): Total dsDNA quantification was performed using the assay kit Quant-iT ${ }^{\mathrm{TM}}$ PicoGreen $^{\circledR}$ (Life Technologies). Samples were aspirated and transferred to $1 \mathrm{~mL}$ centrifuge tubes. Following centrifugation at $300 \mathrm{~g}$ for $5 \mathrm{~min}$, the supernatant was discarded and samples were suspended in ultra-pure sterile water ( $1 \mathrm{~mL}$ per sample) for cell lysis. After $1 \mathrm{~h}$ in a $37^{\circ} \mathrm{C}$ shaking water bath, samples were frozen at $-80^{\circ} \mathrm{C}$ at least overnight. Samples were defrosted and used according to the specifications of the kit. A standard curve for DNA analysis was generated with the provided dsDNA solution. After 10 min of incubation at RT, fluorescence was read at an excitation wavelength of 485/20 nm and 528/20 nm of emission using a microplate reader (Gen 5, Synergy HTX, Biotek). Samples resultant from cell lysis were also used for the quantification of the activity of alkaline phosphatase. A substrate solution ( $\mathrm{pH} 9.8$ ) was prepared by dissolving 4nitrophenylphosphate disodium salt hexahydrate $(0.2 \% \mathrm{w} / \mathrm{v}$, Merck) in diethanolamine $(1 \mathrm{M}$, Sigma-Aldrich). Each sample (20 $\mu \mathrm{L}$, in triplicate) was mixed with the prepared substrate solution $(60 \mu \mathrm{L})$. After $45 \mathrm{~min}$ at $37^{\circ} \mathrm{C}$ protected from light, the reaction was stopped $(80 \mu \mathrm{L})$ with sodium hydroxide $(2 \mathrm{M})$ and EDTA $(0.2 \mathrm{mM})$. A standard curve with a range of concentrations was prepared by diluting 4-nitrophenol solution (10 mM, Merck) in the stop solution. Absorbance was read at $405 \mathrm{~nm}$ in a microplate reader (Synergy HTX, Biotek). Statistical analysis was performed using two-way analysis of variance (ANOVA) with Tukey's post-hoc test (GraphPad Prism 6.0). A p-value <0.05 was considered statistically significant. Only non-significant differences (ns) were marked to facilitate the interpretation of the data. All results are presented as mean $\pm \mathrm{SD}$.

Scanning Electron Microscopy (SEM): Microcapsules were fixed at RT in formalin (10\% v/v) for $30 \mathrm{~min}$, and subsequently dehydrated in increasing gradient series of ethanol (10 min each). The membrane of microcapsules was destroyed to expose the core contents. After gold sputtering, samples were visualized ( $25 \mathrm{kV}$, S4100, Hitachi). 


\section{WILEY-VCH}

CD31 immunofluorescence staining of 2D cell beds: Following 48h of HUVECs seeding, 2D cell beds were fixed in formalin $(10 \% \mathrm{v} / \mathrm{v})$ for $30 \mathrm{~min}$ at RT, and permeabilized for $5 \mathrm{~min}$ at RT with Triton X-100 (0.1\% v/v, Merck). Prior to cell seeding, HUVECs were labelled with DiL ( $1 \mathrm{~mL}$ containing $2 \mu \mathrm{M}$ per $1 \times 10^{6}$ cells) at $37^{\circ} \mathrm{C}$ for $15 \mathrm{~min} .2 \mathrm{D}$ cell beds composed by fibroblasts co-cultured with HUVECs-DiL or HUVECs-DiL alone were then immersed in FBS/PBS (5\% $\mathrm{w} / \mathrm{v}$ ) for $1 \mathrm{~h}$ at $\mathrm{RT}$ to block non-specific binding, and then incubated overnight at $4^{\circ} \mathrm{C}$ with the primary antibody mouse anti-human CD31 (Biolegend, 1:100 in 5\% FBS/PBS). After PBS washing, samples were incubated for $1 \mathrm{~h}$ at RT with the secondary antibody anti-mouse AlexaFluor 488 (Biolegend, 1:500 in 5\% FBS/PBS). After PBS washing, samples were counterstained with 4',6-diamidino-2-phenylindole, dihydrochloride (DAPI, 1 mg.mL ${ }^{-1}$ diluted 1:1000 in PBS, ThermoFisher Scientific) for $5 \mathrm{~min}$ at RT, and analyzed by fluorescence microscopy (Axio Imager 2, Zeiss).

F-actin filaments fluorescence staining: Microcapsules were fixed at RT in formalin (10\% v/v) for $30 \mathrm{~min}$, and permeabilized for $5 \mathrm{~min}$ at RT with Triton X-100 (0.1\% v/v). Samples were stained with phalloidin (Flash Phalloidin Red 594, 1:40 in PBS, Biolegend) for 45 min at RT, and then counterstained with DAPI (1 mg.mL ${ }^{-1}$ diluted 1:1000 in PBS) for $5 \mathrm{~min}$ at RT. Microcapsules were analyzed by fluorescence microscopy (Axio Imager 2, Zeiss).

Calcein-AM fluorescence staining: Microcapsules encapsulating MC3T3-E1 and PCL microparticles stained with nile red were immersed in a PBS $(1 \mathrm{~mL})$ solution containing calcein$\mathrm{AM}(1 \mu \mathrm{L})$ for $15 \mathrm{~min}$ at $37^{\circ} \mathrm{C}$. After PBS washing, samples were immediately visualized by fluorescence microscopy (Axio Imager 2, Zeiss).

Chick chorioallantoic membrane (CAM) assay: The CAM assay was used to evaluate the angiogenic response of microcapsules. After EHDA production, microcapsules (total infused: 


\section{WILEY-VCH}

$10 \mathrm{~mL}$ alginate) were incubated at $37^{\circ} \mathrm{C}$ and $5 \% \mathrm{CO}_{2}$ in serum-free Gibco ${ }^{\circledR}$ MEM $\alpha(20 \mathrm{~mL})$ supplemented with antibiotic-antimycotic (1\% v/v). After an overnight incubation, microcapsules were implanted in fertilized chicken (gallus gallus) eggs, obtained from commercial sources, which were previously incubated horizontally at $37.8{ }^{\circ} \mathrm{C}$ in a humidified atmosphere for 10 days. A square window was opened in the shell after removal of $2-2.5 \mathrm{~mL}$ of albumen, to allow detachment of the developing CAM. The window was sealed with adhesive tape and the eggs returned to the incubator. Microcapsules $(20 \mu \mathrm{L})$ were transferred to a $3 \mathrm{~mm}$ silicone ring under sterile conditions. CAMs without microcapsules and supplemented with basic fibroblast growth factor (bFGF, $500 \mathrm{ng}$ ) or with Gibco® MEM $\alpha$ supplemented with antibiotic-antimycotic $(1 \% \mathrm{v} / \mathrm{v})$ were used as positive and negative controls, respectively. The eggs were re-sealed and returned to the incubator for 3 days. After removing the silicone ring, CAMs were excised from the embryos and visualized ex-ovo under light microscopy (SZX16 coupled with a DP71 camera, Olympus). The number of new vessels ( $<20 \mu \mathrm{m}$ in diameter) growing radially towards the inoculation site were counted blinded. Statistical analysis was carried out using GraphPad Prism 6 software. Data is presented as mean \pm standard deviation (SD) from 10 eggs $(n=3)$. A using two-way analysis of variance (ANOVA) with Kruskal-Wallis test was used. A p-value $<0.05$ was considered statistically significant.

\section{Supporting Information}

Supporting Information is available from the Wiley Online Library or from the author.

\section{Acknowledgements}

The authors acknowledge the funding from the European Research Council (ERC) for project ATLAS (ERC-2014-ADG-669858), and the Portuguese Foundation for Science and Technology (FTC) for project CIRCUS (PTDC/BTM-MAT/31064/2017). This work was 


\section{WILEY-VCH}

developed within the scope of the project CICECO-Aveiro Institute of Materials, FCT Ref. UID/CTM/50011/2019, financed by national funds through the FCT/MCTES. This work was also partly supported by Japan Society for the Promotion of Science (JSPS) Bilateral Open Partnership Joint Research Projects. The authors are also grateful to A. Sofia Silva (Figure 3A and 4D) and Vítor M. Gaspar (Figure 3E) for LSCM imaging. Image acquisition was performed in the LiM facility of iBiMED, a node of PPBI (Portuguese Platform of BioImaging) with grant agreement number POCI-01-0145-FEDER-022122.

Received: ((will be filled in by the editorial staff))

Revised: ((will be filled in by the editorial staff)) Published online: ((will be filled in by the editorial staff))

References

[1] C. R. Correia, R. L. Reis, J. F. Mano, Adv. Healthc. Mater. 2018, 7, 1701444.

[2] J. Li, D. J. Mooney, Nat. Rev. Mater. 2016, 1, DOI 10.1038/natrevmats.2016.71.

[3] O.-W. Merten, Philos. Trans. R. Soc. Lond. B. Biol. Sci. 2015, 370, 20140040.

[4] C. R. Correia, R. L. Reis, J. F. Mano, Biomacromolecules 2013, 14, 743.

[5] C. R. Correia, P. Sher, R. L. Reis, J. F. Mano, Soft Matter 2013, 9, 2125.

[6] C. R. Correia, S. Gil, R. L. Reis, J. F. Mano, Adv. Healthc. Mater. 2016, 5, 1346.

[7] C. R. Correia, R. P. Pirraco, M. T. Cerqueira, A. P. Marques, R. L. Reis, J. F. Mano, Sci. Rep. 2016, 6, 21883.

[8] C. R. Correia, T. C. Santos, R. P. Pirraco, M. T. Cerqueira, A. P. Marques, R. L. Reis, J. F. Mano, Acta Biomater. 2017, 53, 483.

[9] S. K. Boda, X. Li, J. Xie, J. Aerosol Sci. 2018, 125, 164.

[10] D. N. Nguyen, C. Clasen, G. Van den Mooter, J. Pharm. Sci. 2016, 105, 2601.

[11] Y. Xin, G. Chai, T. Zhang, X. Wang, M. Qu, A. Tan, M. Bogari, M. Zhu, L. Lin, Q. Hu, et al., Biomed. Reports 2016, 5, 723. 


\section{WILEY-VCH}

[12] Z. McCrea, Y. Arnanthigo, S.-A. Cryan, S. O’Dea, J. Med. Biol. Eng. 2018, 38, 497.

[13] J. Wang, J. A. Jansen, F. Yang, Front. Chem. 2019, 7, 258.

[14] J. Borges, L. C. Rodrigues, R. L. Reis, J. F. Mano, Adv. Funct. Mater. 2014, 24, 5624.

[15] J. M. Silva, N. Georgi, R. Costa, P. Sher, R. L. Reis, C. a Van Blitterswijk, M. Karperien, J. F. Mano, PLoS One 2013, 8, 1.

[16] S. M. Oliveira, V. E. Santo, M. E. Gomes, R. L. Reis, J. F. Mano, Biomaterials 2015, $48,56$.

[17] T. D. Gomes, S. G. Caridade, M. P. Sousa, S. Azevedo, M. Y. Kandur, E. T. Öner, N. M. Alves, J. F. Mano, Acta Biomater. 2018, 69, 183.

[18] M. N. Nakatsu, R. C. A. Sainson, J. N. Aoto, K. L. Taylor, M. Aitkenhead, S. Pérezdel-Pulgar, P. M. Carpenter, C. C. W. Hughes, Microvasc. Res. 2003, 66, 102.

[19] B. Andrée, H. Ichanti, S. Kalies, A. Heisterkamp, S. Strauß, P.-M. Vogt, A. Haverich, A. Hilfiker, Sci. Rep. 2019, 9, 5437.

[20] X. Fan, Y. Teng, Z. Ye, Y. Zhou, W.-S. Tan, J. Cell Sci. 2018, 131, jcs216135.

[21] M. C. Moorer, J. P. Stains, Curr. Osteoporos. Rep. 2017, 15, 24.

[22] L. I. Plotkin, T. Bellido, Bone 2013, 52, 157.

[23] F. Villars, B. Guillotin, T. Amédée, S. Dutoya, L. Bordenave, R. Bareille, J. Amédée, Am. J. Physiol. Physiol. 2002, 282, C775.

[24] Y. Chen, M. Chen, T. Xue, G. Li, D. Wang, P. Shang, J. X. Jiang, H. Xu, J. Cell. Physiol. 2019, jcp. 28581.

[25] B. Guillotin, R. Bareille, C. Bourget, L. Bordenave, J. Amédée, Bone 2008, 42, 1080.

[26] N. Mitrousis, A. Fokina, M. S. Shoichet, Nat. Rev. Mater. 2018, 3, 441. 


\section{WILEY-VCH}

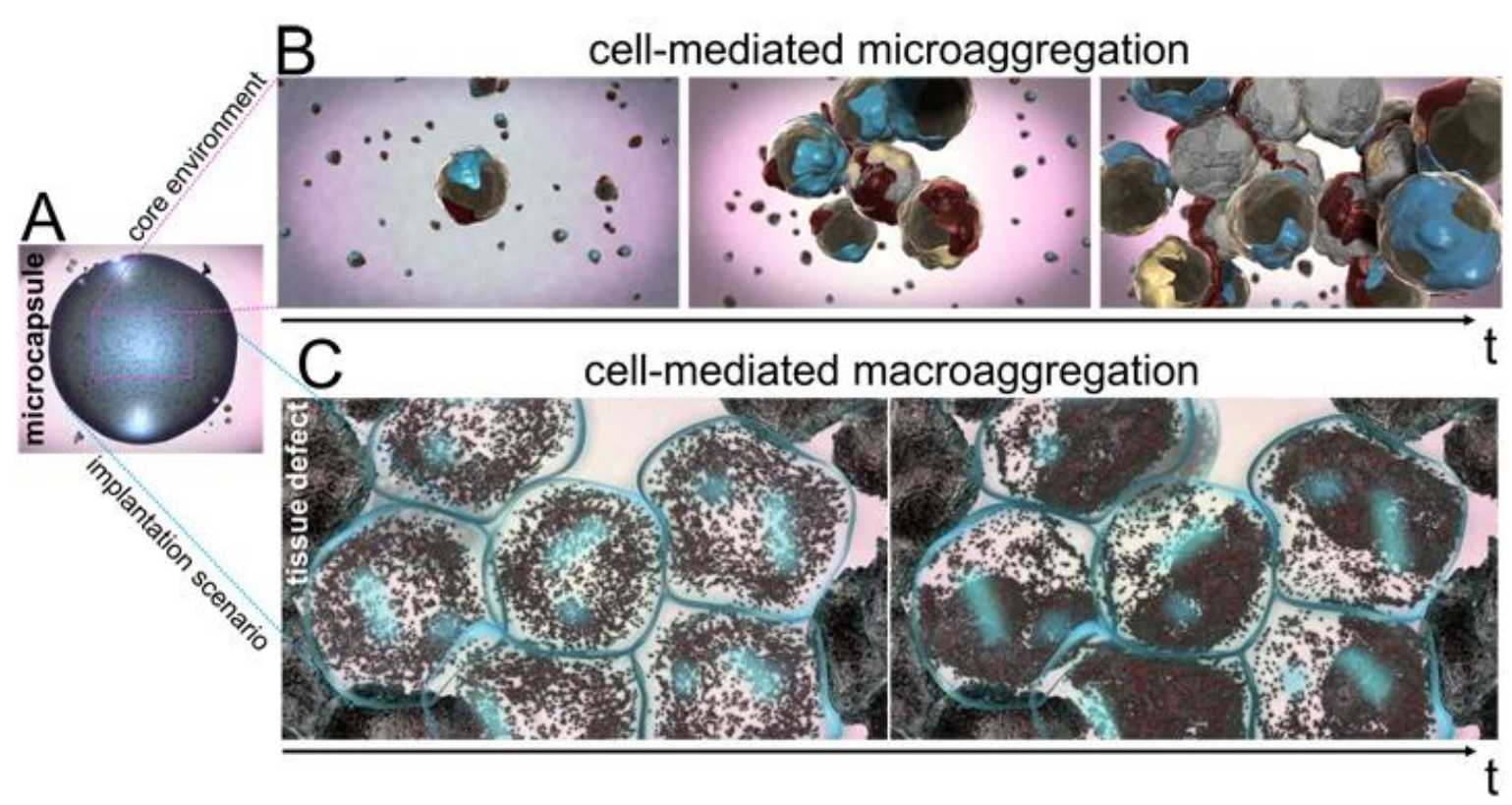

Figure 1 - Schematic representation of the microcapsules system proposed. (A) Overview of a liquefied and multilayered capsule composed by a permselective membrane that allows the entrance of essential molecules for cells survival and avoids the entrance of high molecules and other cells. (B) Cells and microparticles encapsulated within the liquefied core can move freely. Inside the microcapsules, different cell phenotypes can be combined, and besides proliferation, cells can undergo differentiation. (C) After implantation, microcapsules can easily adapt to a tissue defect, and agglomerate to form macrostructures able to fulfil a large defect. 


\section{WILEY-VCH}
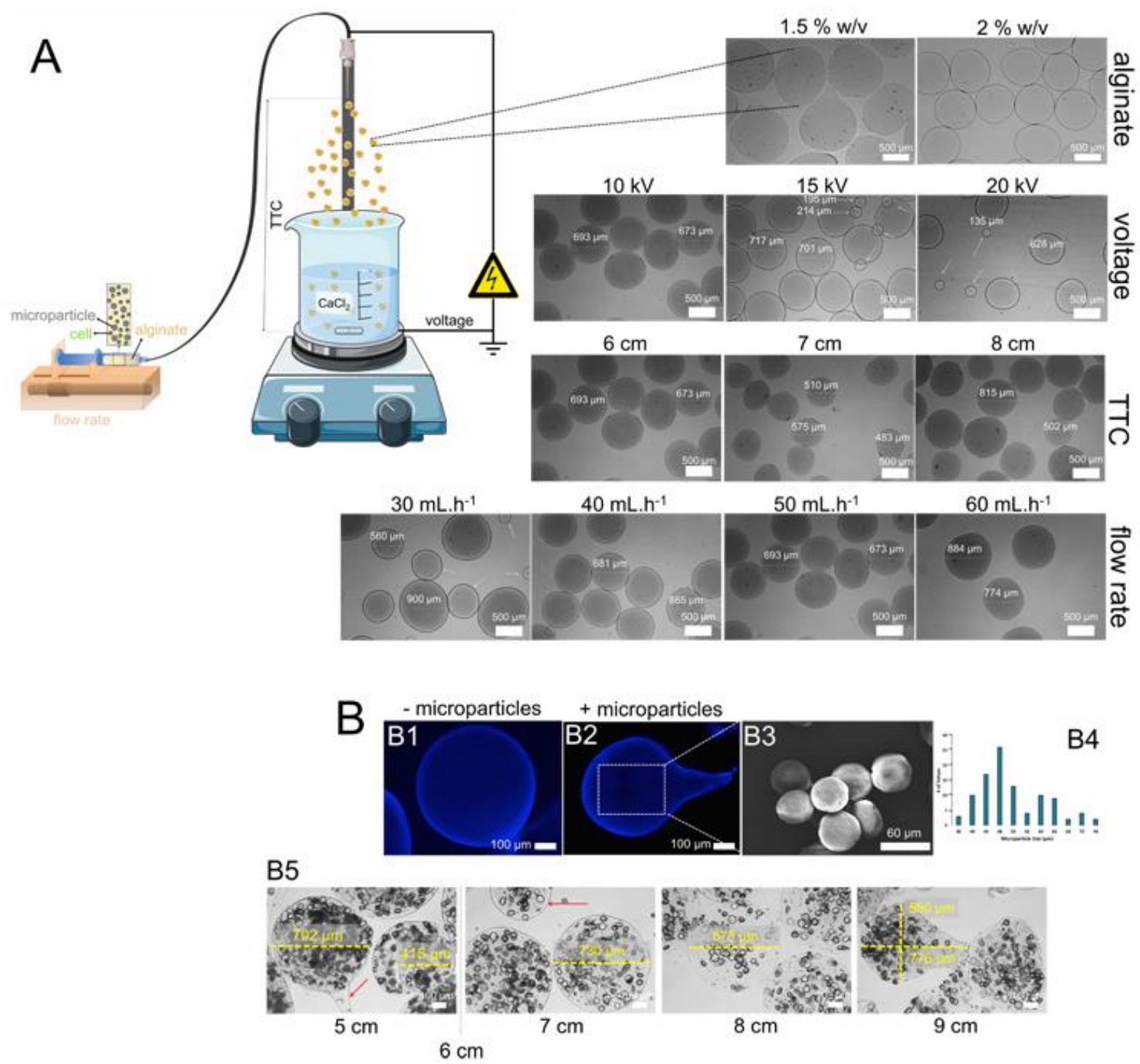

Figure 2 - Representative images of the optimization process to obtain alginate hydrogels by electrohydrodynamic atomization (EHDA). (A) Different parameters of the process were tested to obtain empty alginate hydrogels, namely the alginate concentration $(\% \mathrm{w} / \mathrm{v})$, the flow rate $\left(30,40,50\right.$, and $\left.60 \mathrm{~mL} \cdot \mathrm{h}^{-1}\right)$, the distance between the tip to the collector (TTC 6,7 , and $8 \mathrm{~cm}$ ), and the applied voltage $(10,15$, and $20 \mathrm{kV})$. Constant parameters: $2 \% \mathrm{w} / \mathrm{v}$ alginate, $50 \mathrm{~mL} \cdot \mathrm{h}^{-1}$ flow rate, TTC $6 \mathrm{~cm}$, and $10 \mathrm{kV}$ of applied voltage. (B) Optimization of the TTC required to obtain spherical alginate hydrogels containing microparticles. (B1) Empty alginate hydrogel produced by EHDA at $2 \% \mathrm{w} / \mathrm{v}, 50 \mathrm{~mL} \cdot \mathrm{h}^{-1}, 6 \mathrm{~cm}$, and $10 \mathrm{kV}$. (B2) Alginate hydrogels encapsulating microparticles produced by EHDA using the same parameters of (B1). (B3) SEM image of the polycaprolactone microparticles produced by oil/water emulsion. (B4) Histogram 


\section{WILEY-VCH}

of the diameter frequency of the microparticles. (B5) Representative images of the optimization process to obtain alginate hydrogels loaded with microparticles by testing different TTC of the EHDA process using $2.5 \% \mathrm{w} / \mathrm{v}$ alginate, $50 \mathrm{~mL} \cdot \mathrm{h}^{-1}$ flow rate, and $10 \mathrm{kV}$ of voltage.

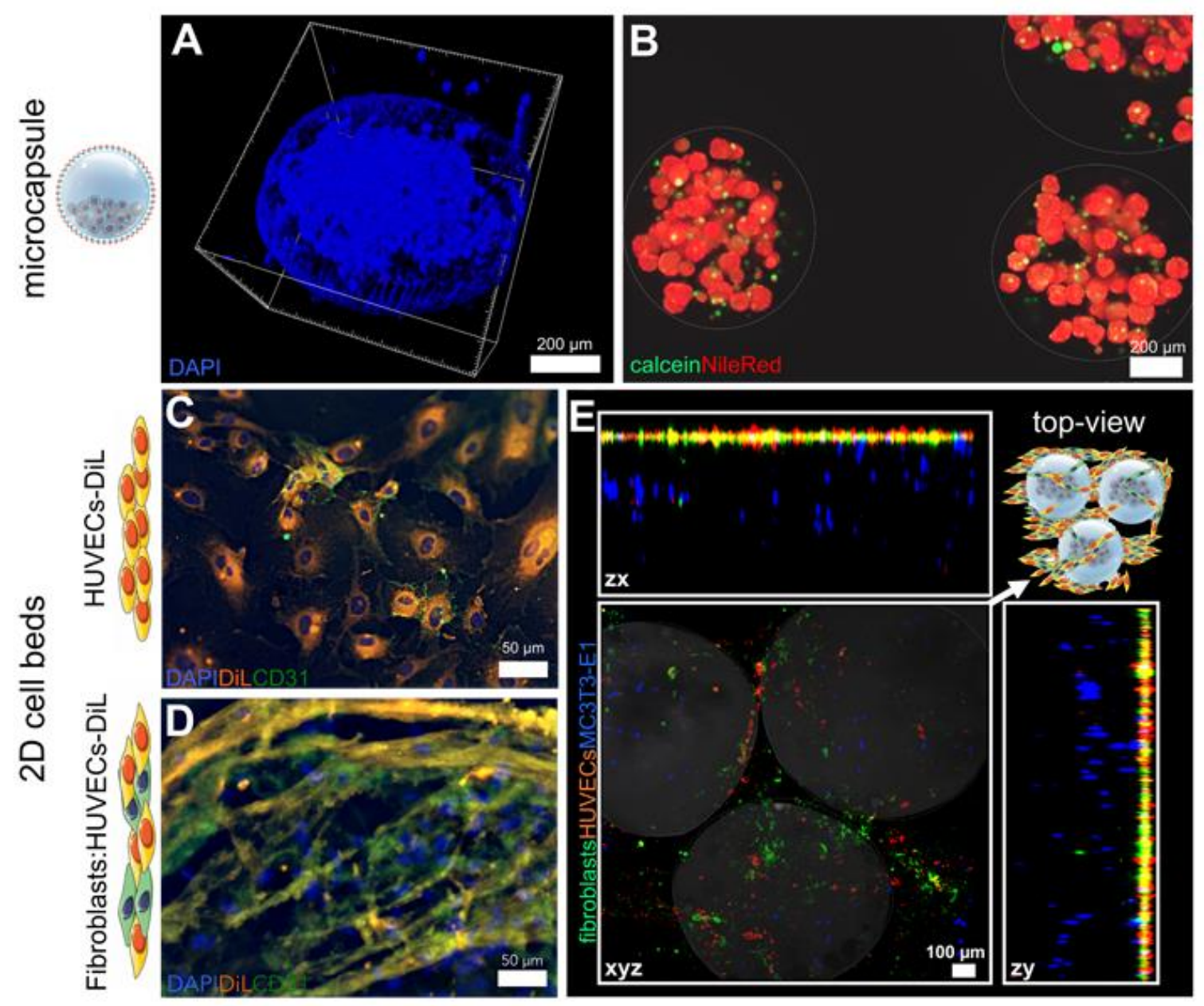

Figure 3 - (A) Overview of a liquefied microcapsule encapsulating MC3T3-E1 cells and polycaprolactone (PCL) microparticles visualized by laser scanning confocal microscopy (LSCM). Cell nuclei was stained with DAPI (blue). Scale bar is $200 \mu \mathrm{m}$. (B) Microcapsules encapsulating living MC3T3-E1 cells stained with calcein (green) and PCL microparticles fluorescently marked with nile red. Scale bar is $200 \mu \mathrm{m}$. (C) Immunofluorescence of CD31 (green) in a 2D co-culture of fibroblast and HUVECs fluorescently marked with DiL (orange). 


\section{WILEY-VCH}

Cell nuclei was stained with DAPI (blue). Scale bar is $50 \mu \mathrm{m}$. (D) Immunofluorescence of CD31 (green) in a 2D culture of HUVECs fluorescently marked with DiL (orange). Cell nuclei was stained with DAPI (blue). Scale bar is $50 \mu \mathrm{m}$. (E) LSCM of the triple sequential co-culture system composed by microcapsules encapsulating MC3T3-E1 cells and PCL microparticles localized at the top of a 2D co-culture of fibroblasts and HUVECs. Fibroblasts, HUVECs, and MC3T3-E1, were previously stained with DiO (green), DiL (orange), and DiD (blue). Scale bar is $100 \mu \mathrm{m}$. 


\section{WILEY-VCH}
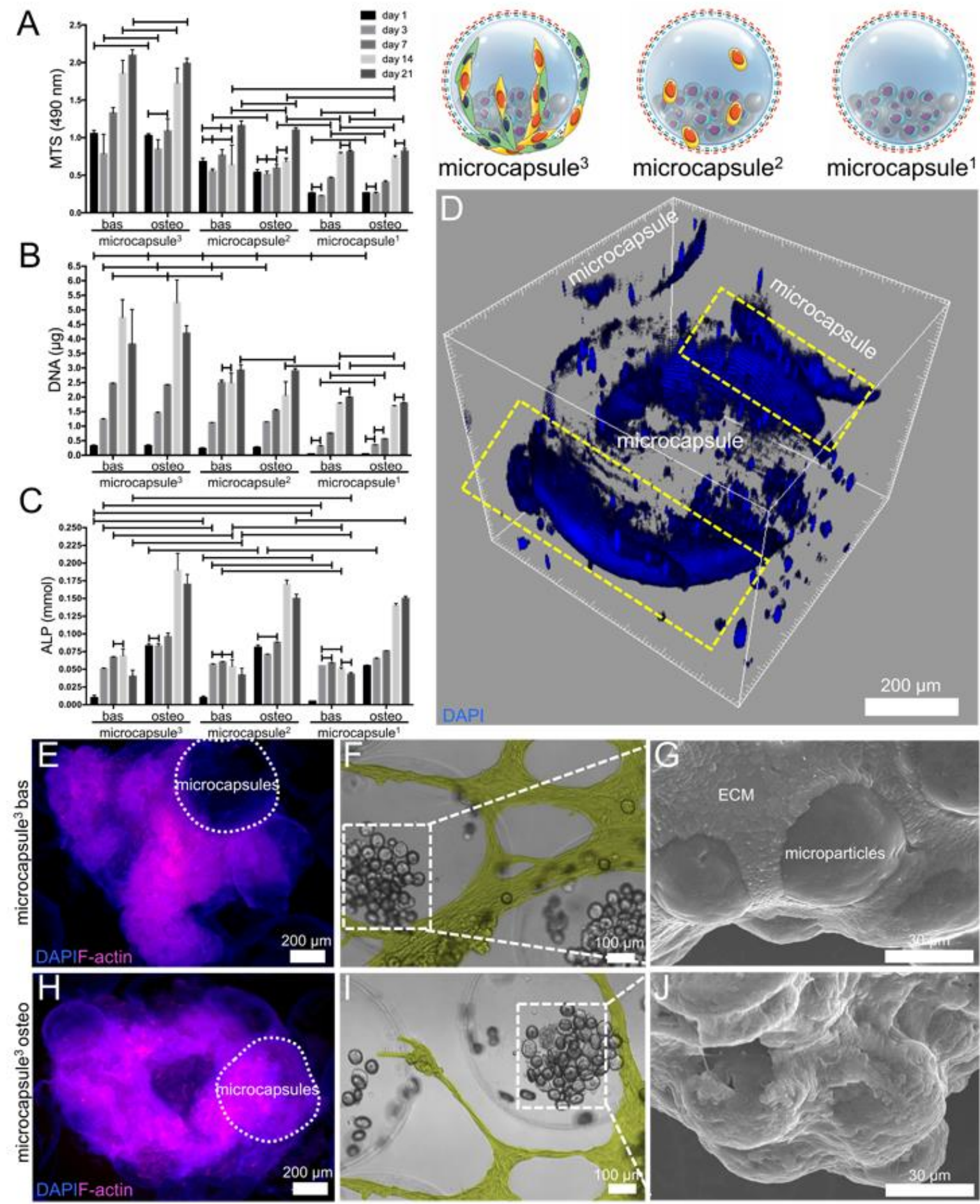

Figure 4 - (A) Metabolic activity measured at $490 \mathrm{~nm}$ by MTS colorimetric assay read, (B) cell proliferation evaluation by DNA quantification $(\mu \mathrm{g})$, and $(\mathbf{C})$ alkaline phosphatase (ALP) activity quantification (mmol) of microcapsules encapsulating MC3T3-E1 cells and polycaprolactone (PCL) microparticles and in contact with $(i)$ a co-culture of fibroblasts and HUVECs (microcapsule ${ }^{3}$ ), (ii) a mono-culture of HUVECs (microcapsule ${ }^{2}$ ), or (iii) alone 


\section{WILEY-VCH}

$\left(\right.$ microcapsule $\left.^{1}\right)$. Results are presented as mean \pm standard deviation. Only statistically nonsignificant differences are marked, otherwise results are significantly different. (D) Overview of a liquefied microcapsule encapsulating MC3T3-E1 cells and PCL microparticles. After 8h of incubation, microcapsules were visualized by laser scanning confocal microscopy (LSCM). Cell nuclei was stained with DAPI (blue). The migration ability of cells from the 2D environment to the 3D structure provided by the RGD-membrane of microcapsules is highlighted by the yellow squares. Scale bar is $200 \mu \mathrm{m}$. (E and H) Macroaggregates of microcapsules assembled by fibroblasts and HUVECs after 7 days of culture in (E) basal (bas) or (H) osteogenic differentiation (osteo) media. Samples were visualized by fluorescence microscopy. F-actin filaments were stained by phalloidin (pink). Cell nuclei was stained with DAPI (blue). Scale bars are $200 \mu \mathrm{m}$. (F and I) Interaction of the network created by fibroblasts and HUVECs and its interaction with the microcapsules after 3 days of culture in (F) bas or (I) osteo media. Samples were visualized by light microscopy. Scale bars are $100 \mu \mathrm{m}$. (G and J) SEM images of the microaggregates composed by encapsulated MC3T3-E1 cells and PCL microparticles formed inside the liquefied core of microcapsules after 7 days of culture in (G) bas or $(\mathbf{J})$ osteo media. Scale bars are $30 \mu \mathrm{m}$. 


\section{WILEY-VCH}

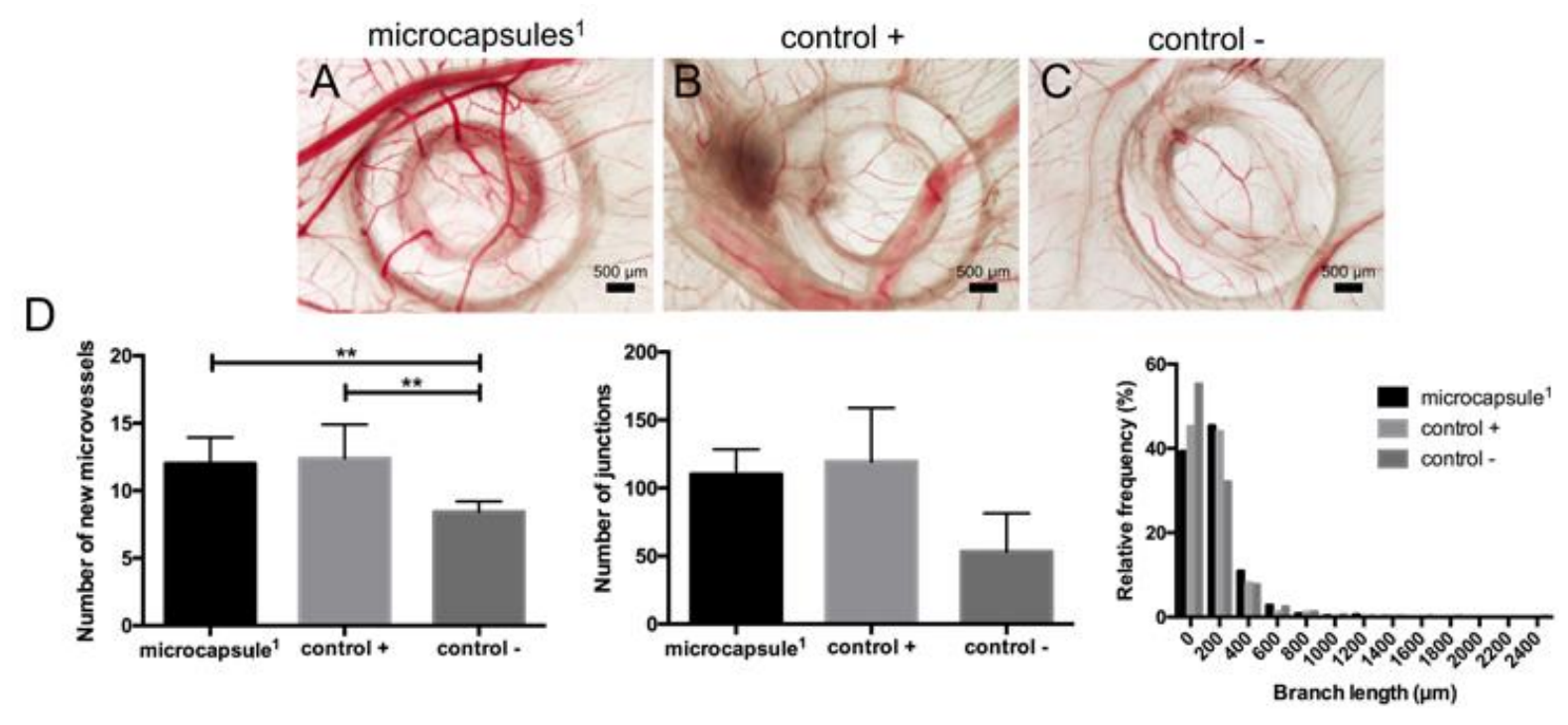

Figure 5 - Pro-angiogenic ability of microcapsules using the chick chorioallontoic membrane (CAM) assay. Optical microscopy of CAMs inoculated with (A) microcapsule ${ }^{1}$, (B) basic fibroblast growth factor-2 (bFG-2, control + ), and (C) $\alpha$-MEM/1\% penicillin/streptavidin (control -). Quantification normalized per area of a well-defined Region of Interest of the (C) number of new recruited microvessels $(<20 \mu \mathrm{m})$, number of junctions, and branch length $(\%$ relative frequency). Scale bars are $50 \mu \mathrm{m}(* * \mathrm{p}<0.01)$. 


\section{WILEY-VCH}

Liquefied microcapsules are produced at high rates by electrohydrodynamic atomization. Microcapsules present a multilayered membrane enriched with RGD domains to allow their cell-mediated aggregation. Simultaneously, cell-mediated aggregations occur at the liquefied core of microcapsules encapsulating cells and microparticles. The bottom-up concept is here term as $3 \mathrm{D}+3 \mathrm{D}$. The system also present angiogenic ability, as successfully demonstrated using a CAM model.

\section{Liquefied systems}

C.R. Correia*, I.M. Bjørge, J. Zeng, M. Matsusaki, J.F. Mano*

Liquefied microcapsules as dual-microcarriers for 3D+3D bottom-up tissue engineering

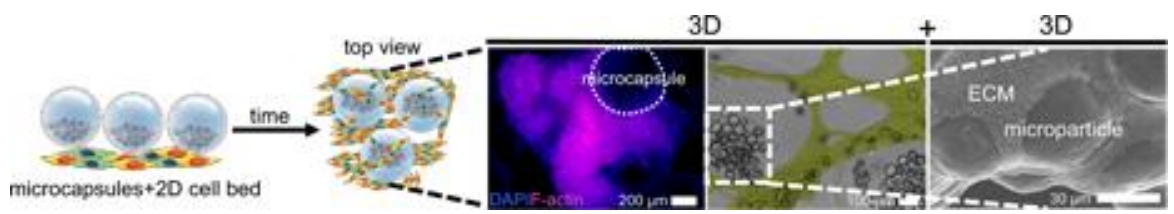




\section{WILEY-VCH}

Copyright WILEY-VCH Verlag GmbH \& Co. KGaA, 69469 Weinheim, Germany, 2018.

\section{Supporting Information}

\section{Liquefied microcapsules as dual-microcarriers for 3D+3D bottom-up tissue engineering}

Clara R. Correia*, Isabel M. Bjфrge, Jinfeng Zeng, Michiya Matsusaki, João F. Mano*

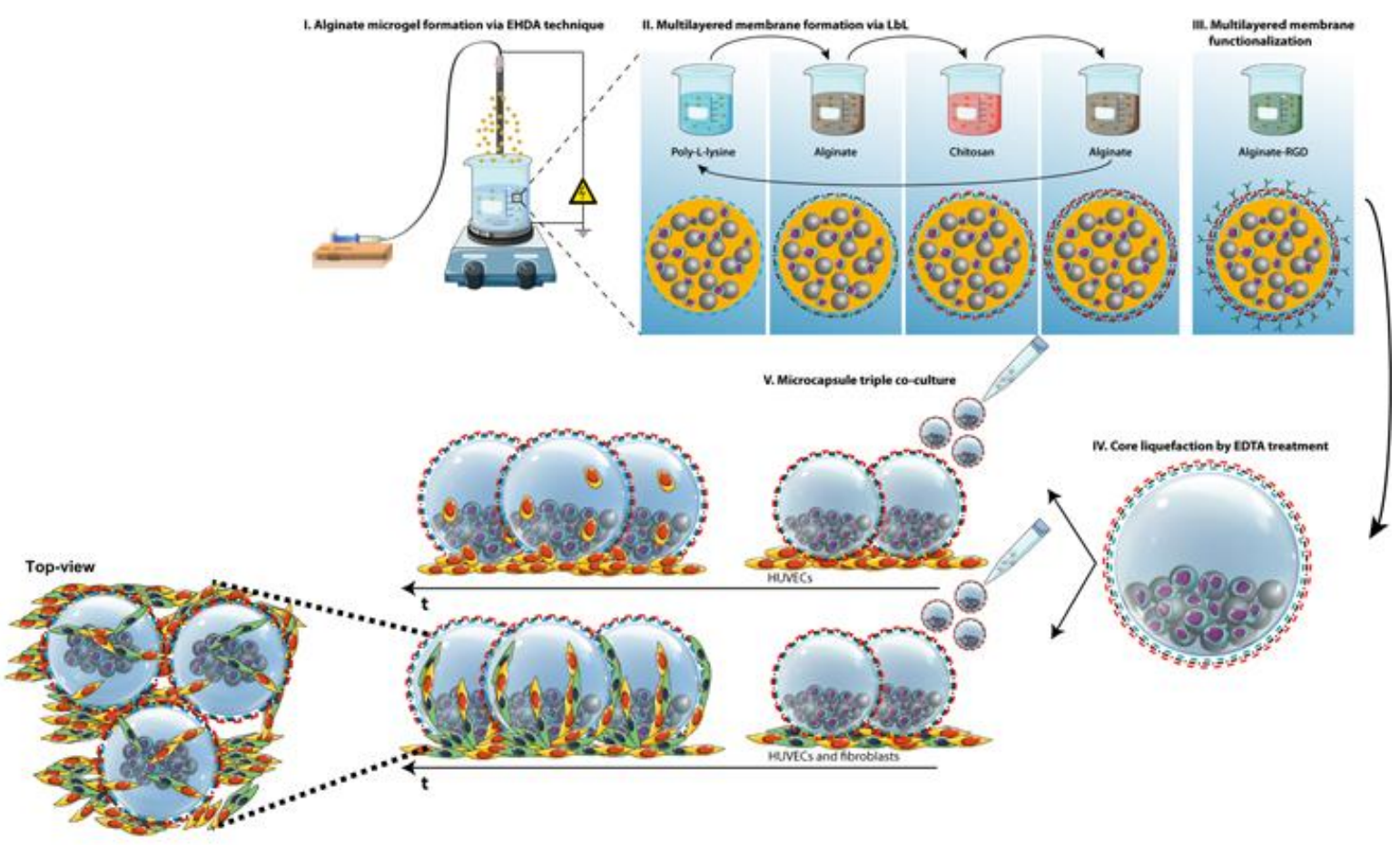

Figure S1 - Schematic representation of the production of liquefied and multilayered microcapsules, and the experimental design of the study. (I) Alginate microgels loaded with cells and microparticles are obtained by electrohydrodynamic atomization (EHDA) technique. Different parameters of the process are optimized, namely the alginate concentration, the flow rate, the distance between the tip to the collector, and the applied voltage. (II) Microgels are used as templates to produce a multilayered membrane through the assembly of three polyelectrolytes, poly(L-lysine), alginate, and chitosan, by the layer-by-layer (LbL) technique. (III) The last layer of microgels is functionalized by combining alginate with the cell-adhesive motif arginyl-glycyl-aspartic acid (RGD). (IV) Coated microgels are immersed in 


\section{WILEY-VCH}

ethylenediaminetetraacetic acid (EDTA) to liquefy the alginate core. (V) The obtained liquefied and multilayered microcapsules are transferred to the top of previously formed $2 \mathrm{D}$ cell beds composed by HUVECs alone or co-cultured with fibroblasts. With time, 2D cell beds start to migrate towards the multilayer of microcapsules, leading to the formation of macroaggregates. Simultaneously, the encapsulated cells and microparticles interact inside the liquefied core, and create microaggregates. The concept is herein termed as 3D+3D bottom-up tissue engineering.
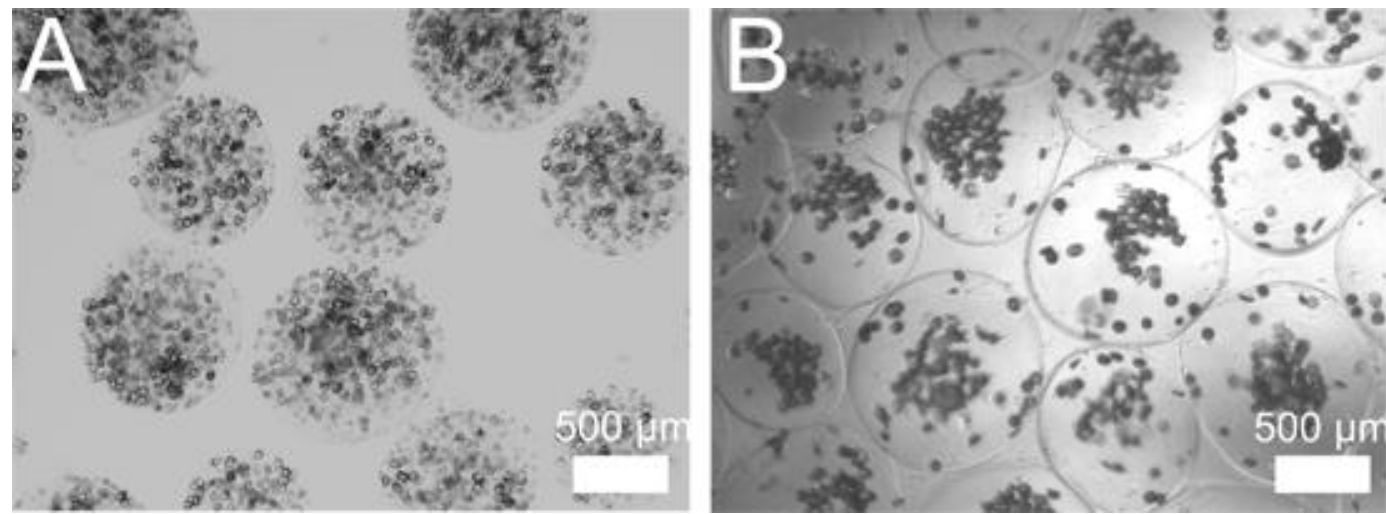

Figure S2 - Microparticles and cells encapsulated in (A) alginate microgels or (B) liquefied and multilayered microcapsules. Scale bars are $500 \mu \mathrm{m}$.
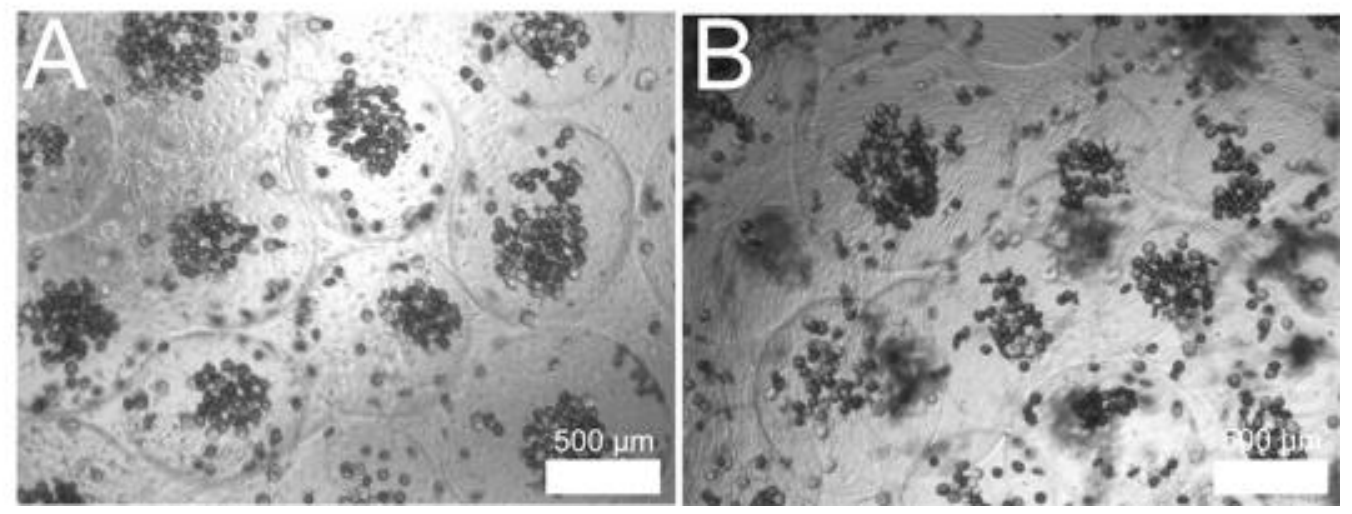

Figure S3 - Liquefied and multilayered microcapsules presenting in the last layer poly $(\mathrm{L}-$ lysine). Microcapsules are cultured on top of 2D cell beds composed by (A) HUVECs alone or (B) co-cultured with fibroblasts. Scale bars are $500 \mu \mathrm{m}$. 


\section{WILEY-VCH}

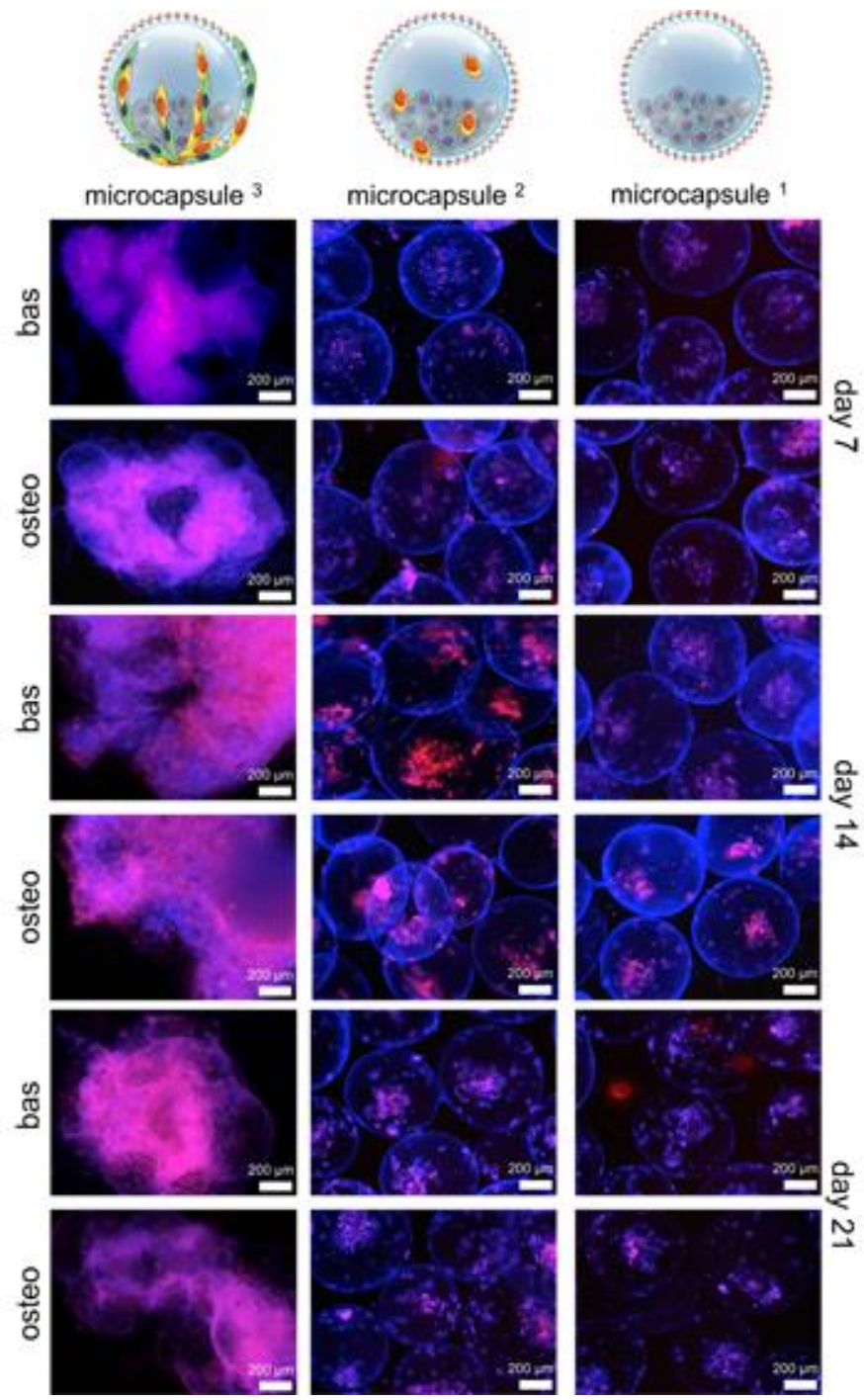

Figure S4 - Fluorescence microscopy visualization of (i) microcapsules encapsulating MC3T3-E1 cells and polycaprolactone (PCL) microparticles, and in contact with a co-culture of fibroblasts and HUVECs (microcapsule ${ }^{3}$ ), (ii) microcapsules encapsulating MC3T3-E1 cells and polycaprolactone (PCL) microparticles, and in contact with a mono-culture of HUVECs (microcapsule ${ }^{2}$ ), and (iii) microcapsules encapsulating MC3T3-E1 cells and polycaprolactone (PCL) microparticles alone (microcapsule ${ }^{1}$ ). Cell nuclei was stained with DAPI (blue), and Factin filaments with phalloidin (pink). Samples were cultured in basal (bas) or osteogenic differentiation (osteo) media and visualized at day 7, 14, and 21 post-encapsulation. Scale bars are $200 \mu \mathrm{m}$. 


\section{WILEY-VCH}
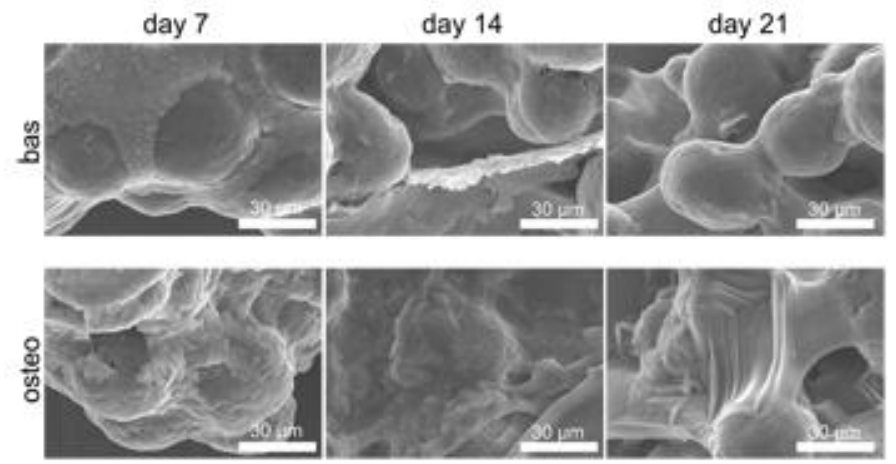

Figure S5 - SEM images of the microaggregates composed by encapsulated cells and PCL microparticles, and formed inside the liquefied environment of microcapsules ${ }^{3}$. Microcapsules were cultured in bas or osteo media and visualized at day 7, 14, and 21 post-encapsulation. Scale bars are $30 \mu \mathrm{m}$. 
Figure 1

Click here to access/download Production Data Figure1(new-letters)-100dpi.tif 
Figure 2

\section{Click here to access/download Production Data Figure2(100dpi).tif}


Figure 3

Click here to access/download

\section{Production Data \\ Figure3(new-arrow)-100dpi.tif}


Figure 4

Click here to access/download

\section{Production Data \\ Figure4(new)-100.tif}


Figure 5

\section{Click here to access/download \\ Production Data Figure5(100dpi).tif}


Figure S1

\section{Click here to access/download Production Data
Figures1(new-topview)-100dpi.tif \\ Production Data
Figures1(new-topview)-100dpi.tif}

(

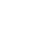


Figure S2

Click here to access/download

\section{Production Data \\ FigureS2(new)-100.tif}


Click here to access/download

Figure S4

\section{Production Data \\ FigureS4(100dpi).tif}


Click here to access/download Production Data ToC(600dpi).tif 